\title{
The influence of anti-cyclic citrullinated peptide on anticentromere antibody-positive rheumatoid arthritis patients
}

\author{
La-He Jearn and Think-You Kim* \\ See related research by Bournia et al., http://arthritis-research.com/content/12/2/R47, and related letter by Vlachoyiannopoulos and Bournia, \\ http://arthritis-research.com/content/12/5/407
}

We read with interest the paper of Bournia and colleagues that anticentromere antibody (ACA)-positive primary Sjögren's syndrome (SS) shows a clinical phenotype intermediate between ACA-negative SS and systemic sclerosis (SSc) [1]. In our past study investigating the clinical features of 62 patients with positive ACA, only one patient had typical CREST syndrome, 9 patients had Raynaud's phenomenon (8 with sclerodactyly, telangiectasia or calcinosis), while rheumatoid arthritis (RA) was the most common diagnosis (21 patients) [2]. Thereafter, we investigated whether ACA-positive RA patients have distinctive clinical features compared to general RA patients [3] and found that the high titer group (over 1:320) was associated with Raynaud's phenomenon more often. This result suggests that RA patients are also affected by high titer ACA, similar to SS patients.

Recently, anti-cyclic citrullinated peptide (anti-CCP) has emerged as a useful diagnostic tool in RA. In order to examine any association between anti-CCP and ACA positivity in RA patients, we investigated 81 ACApositive patients using an anti-CCP test from 2007 until May 2010 (Table 1). Interestingly, out of 34 RA patients, $70.6 \%$ (24) were positive for anti-CCP, and there was no case of accompanying Raynaud's phenomenon among them. For ACA-positive RA with negative anti-CCP, only one patient (10\%) had Raynaud's phenomenon, similar to our past result (15.7\%) [3]. In contrast, the incidence of interstitial pulmonary disease was $11.8 \%$ (4 out of 34 ), higher than in our past report (4.2\%) [3], and this was unrelated to anti-CCP positivity. These results suggest that the influence of anti-CCP is greater than ACA in

\footnotetext{
*Correspondence: tykim@hanyang.ac.kr

Department of Early Arthritis/Lab. Medicine, The Hospital for Rheumatic Diseases, Hanyang University Medical Center, 17 Haengdang-Dong, Seongdong-Gu, 133-792, Seoul, Republic of Korea
}

Table 1. The distribution of anticentromere antibodypositive patients according to anti-cyclic citrullinated peptide results

\begin{tabular}{|c|c|c|c|}
\hline & \multicolumn{2}{|c|}{ Anticentromere antibody-positive $(n=81)^{a}$} & \multirow[b]{2}{*}{$P$-value ${ }^{c}$} \\
\hline & $\begin{array}{l}\text { Anti-CCP positive } \\
\quad(n=29)^{b}\end{array}$ & $\begin{array}{l}\text { Anti-CCP negative } \\
\qquad(n=52)\end{array}$ & \\
\hline RA & 24 & 10 & $<0.05$ \\
\hline with Raynaud & $0 / 24$ & $1 / 10$ & 0.116 \\
\hline with sicca & $2 / 24$ & $0 / 10$ & 0.347 \\
\hline with IPD & $3 / 24$ & $1 / 10$ & 0.837 \\
\hline Other diseases ${ }^{d}$ & 5 & 42 & \\
\hline
\end{tabular}

${ }^{\mathrm{a}}$ Anticentromere detected by autoimmune target (AIT) test (ImmunoThink Co., Seoul, Republic of Korea). ${ }^{\mathrm{b}} \mathrm{Anti}-\mathrm{CCP}$ detected by second generation ELISA (Axis-Shield, Dundee Scotland/Immco Diagnostics, Buffalo, USA). 'Chi-square test $(P<0.05)$. ${ }^{\mathrm{d} O}$ Other diseases include systemic sclerosis, systemic lupus erythematosus, Raynaud's phenomenon, Sjögren's syndrome, unspecified rheumatism and osteoarthritis. CCP, cyclic citrullinated peptide; IPD, interstitial pulmonary disease; RA, rheumatoid arthritis.

determining the disease entity and masks even the influence of ACA on the clinical phenotype intermediate with SSc. This is supported by a report that anti-CCP is useful for discriminating between SSc-RA and SSc alone [4].

We think that the influence of anti-CCP on the disease entity is greater than that of ACA. This would mean that the diagnostic impact of disease-associated autoantibodies is different depending on their natures, although they can exert some influence on the expression of specific clinical features. Therefore, although a patient is positive for ACA, we suppose that clinical symptoms may be different depending on the kind of coexisting autoantibody.

(The information in our study was recorded in a manner that subjects cannot be identified directly, so this study was not reviewed by our internal review board under the US Department of Health and Human Services regulations at 45 CFR 46.101(b)(4). Under the same regulations, informed consent was also not required.) 


\section{Abbreviations}

ACA, anticentromere antibody; CCP, cyclic citrullinated peptide; ELISA, enzyme-linked immunosorbent assay; RA, rheumatoid arthritis; SS, Sjögren's syndrome; SSc, systemic sclerosis.

\section{Competing interests}

The authors declare that they have no competing interests.

Published: 29 October 2010

\section{References}

1. Bournia V-KK, Diamanti KD, Vlachoyiannopoulos PG, Moutsopoulos HM: Anticentromere antibody positive Sjögren's syndrome: a retrospective descriptive analysis. Arthritis Res Ther 2010, 12:R47.
2. Kim KS, Kim TY, Kim SY: Diagnostic utility of anti-centromere antibody (I) [abstract]. Korean J Clin Pathol 1994, 14(Suppl):104.

3. Jearn LH and Kim TY: Clinical significance of anti-centromere antibody in rheumatoid arthritis. J Korean Rheum Assoc 2004, 11:159-164.

4. Morita Y, Muro Y, Sugiura K, Tomita Y: Anti-cyclic citrullinated peptide antibody in systemic sclerosis. Clin Exp Rheumatol 2008, 26:542-547.

doi:10.1186/ar3153

Cite this article as: Jearn $L-H$, Kim T-Y: The influence of anti-cyclic citrullinated peptide on anticentromere antibody-positive rheumatoid arthritis patients. Arthritis Research \& Therapy 2010, 12:406. 